IN brief

\section{African GM safety drill}

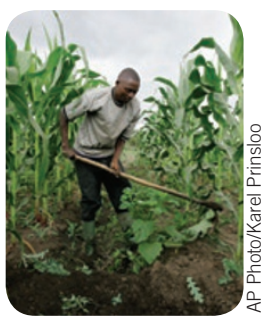

Africa shores up GM crop regulators.
The African Union has set up a school to educate and train future regulators in genetically modified (GM) crop biosafety. The African Biosafety Network of Expertise (ABNE) was officially launched in April in Ouagadougou, Burkina Faso, with a five-year, $\$ 10.4$ million grant from the Bill \& Melinda Gates Foundation. This continent-wide initiative, administered by the African Union's New Partnership for Africa's Development (NEPAD), aims "to build functional biosafety systems," says program director Diran Makinde, who notes that of the 12 African countries that have biotech crop research programs, only 3 have reached the stage of commercialization. A tour of Africa taken in 2008 by Makinde and his staff to assess the nations' different needs highlighted the lack of regulatory expertise. The visiting team concluded that any pan-African solution would need to provide online information resources, training workshops, technical support and partnerships. Today, ABNE's website offers environmental, socioeconomic and food safety advice and information on issues related to GM crops through a live chat function handled by staff. In late March, before the official launch, ABNE hosted a workshop for about 40 regulators in Accra, Ghana, to discuss locally developed, insectresistant transgenic crops. ABNE's staff also took part in a training course last fall at Michigan State University in East Lansing to ramp up their own expertise. These newly minted ABNE trainers are equipped to guide regulators in risk assessment and management issues to enable GM crop adoption. But they will need to learn quickly if they are to succeed in training regulators and consultants across Africa's major languages, according to Theresa Sengooba, a researcher with the International Food Policy Research Institute in Kampala, Uganda. Given the varied state of African biosafety infrastructure, another of ABNE's challenges will be to determine "how best to help countries which are already advanced as well as those which are behind," Sengooba adds. Makinde points out, however, that ABNE enjoys an "added value" from NEPAD's status as a technical arm of the politically well-connected African Union. This supplies the network with the necessary kudos to approach national ministers responsible for agricultural planning and biotech research in African countries. Makinde intends to help two or three additional African countries reach the commercialization stage, and improve regulatory decision-making in the rest within the program's initial budget. "Our main objective," Makinde stresses, "is to contribute to food security in Africa." Lucas Laursen multi-indication situation we're talking about," says Xoma CEO Steven Engle.

Donath was the first to demonstrate that type 2 diabetes has an inflammatory dimension that is mediated by IL-1 $\beta$ (J. Clin. Invest. 110, 851-860, 2002). That work was motivated by an effort to understand how prolonged, excessive glucose levels led to the destruction of insulin-producing pancreatic beta cells. "We observed that everything comes down to an induction of an inflammatory response, which is driven by IL- $1 \beta$," says Donath. He then demonstrated clinical proof of concept, using Kineret (anakinra), an IL-1 $\beta$ inhibitor that is a recombinant, 152-amino acid, nonglycosylated, human N2-L-methionyl IL-1 receptor antagonist (IL-1RA), originally isolated from monocytes (N. Engl. J. Med. 356, 1517-1526, 2007). Kineret competes with IL-1 for binding to the IL-1 receptor type 1 (IL-1R1) on target cells. "That was an earthquake-like shift in thinking," says Engle. A follow-up study showed the effect was sustained. Patients exhibited improved insulin production nine months after receiving the drug (Diabetes Care 32, 1663-1668, 2009).

Although originally approved for treating rheumatoid arthritis, Kineret is rarely used in that indication because of the high doses required owing to its short half-life and to the presence of high levels of IL-1R1 in the joints of rheumatoid arthritis patients. In type 2 diabetes, its long-term use is even more problematic, as pancreatic beta cells express very high concentrations of IL-1R1. "If you want to target the receptor you need a lot of drug," says Donath. IL-1 $\beta$, in contrast, exerts its effects at extremely low concentrations, and it is therefore more amenable to modulation.

Xoma and each of its big pharma rivals already have efficacy testing trials of anti-IL-1 $\beta$ mAbs in type 2 diabetes underway. Interim, three-month data from a six-month phase 2a trial of XOMA 052 in 80 patients is due in the fourth quarter, and a phase $2 \mathrm{~b}$ trial, involving 325 patients, will report in full in the first quarter of 2011. Novartis developed Ilaris at the Novartis Institutes for Biomedical Research, in Cambridge, Massachusetts; its phase $2 / 3$ dose-ranging study in diabetes was initiated in April 2009. Indianapolis-based Lilly's LY2189102, which was developed by scientists now based at the recently opened Lilly Biotechnology Center in San Diego, entered phase 2 testing for diabetes in June 2009. Neither company was willing to comment on their respective programs, however.

Xoma is setting XOMA 052 apart on the basis of its mechanism of action, which is to attenuate rather than eliminate the IL- $1 \beta$ signal (J. Biol. Chem., published online, doi/10.1074/ jbc.M110.115790, 21 April, 2010). Although this $\mathrm{mAb}$ binds the cytokine with ultra-high affinity, it does not block the action of the cytokine completely. "That antibody and IL-1 [complex] can still bind to the receptor but it doesn't give a good signal," says Alan Solinger, Xoma's vice president of clinical immunology. That residual signal could be important, as low levels of the cytokine are required to maintain beta cell activity and proliferation. "If you block IL- $1 \beta$ too much-drop IL-1 $\beta$ to zero-the beta cells cannot function normally," Solinger says.

IL- $1 \beta$ is not the only potential anti-inflammatory target in type 2 diabetes. Startup firm Catabasis Pharmaceuticals last month raised \$39.6 million in series A funding to develop conjugates of salicylate and omega- 3 fatty acids. Both these agents act upstream from the inflammasome, through nuclear factor kappa B (NF- $\kappa \mathrm{B})$, a transcription factor that stimulates production of proIL-1 $\beta$ in response to inflammatory stimuli. "The inflammasome could be an important component of the underlying pathway. I think there's probably more biology left to work out as well," says CEO Jill Milne, who cofounded the Cambridge, Massachusetts-based firm with chief scientific officer Mike Jirousek and Steve Shoelson, of Harvard Medical School and the Joslin Diabetes Center in Boston. They aim to move their first compound, CAT-1904, into clinical studies next year. The Catabasis approach builds on Shoelson's clinical work, which has already shown that highdose salsalate- a dimeric pro-drug of salicylateresulted in a modest improvement in glycemic control in type 2 diabetes patients (Ann. Intern. Med. 152, 346-357, 2010).

By conjugating salicylate with an omega-3 fatty acid, such as eicosapentaenoic acid or docosahexaenoic acid, Catabasis aims to exert a broad effect on the inflammation associated with type 2 diabetes. "All of the approaches to treating inflammation up to this point have focused on trying to inhibit pro-inflammatory pathways," says Jirousek. Catabasis is attempting to stimulate anti-inflammatory signals as well, by exploiting the conversion of omega-3 fatty acids to antiinflammatory eicosanoids. It plans to publish further details on the mechanism it is pursuing. But the basic rationale is to restore normal functioning by means of a synergistic effect of the two compounds. "It's only when the cell is in a stressed state that these molecules have an effect," Jirousek says.

In the meantime, all eyes are on Xoma, which is open to partnering XOMA 052 at any stage. "We haven't restricted ourselves," says Engle. Its patent awards could result in additional licensing income, says Liana Moussatos, analyst at Wedbush Securities, in San Francisco, although she does not expect the company to engage in any major litigation. "They'll go through the motions, but in the end it'll be some kind of cross-licensing deal. That's usually how these things work out. Or maybe Lilly or Novartis will become their partner."

Cormac Sheridan Dublin 